\title{
Introducing Competition to The Middle Level Classroom: Providing for Success
}

Competition is a significant reality of life, but the decision to compete is a personal one, say these writers, who assert that competition must be introduced carefully to middle level students.

\section{By Alfred A. Arth, Lucille M. Freeman, and Edward J. Lawton}

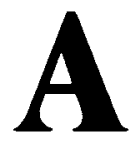

GREAT DEAL of a student's time in school is spent in forced competition with other students. Competitive situations exist whenever one student is in some way held up by the teacher for others to emulate, or whenever students are able to compare achievement levels.

Some examples are those in which grades are read aloud for all to hear, when papers are exchanged to be graded by peers, or when students are required to compete academically within the classroom in such activities as spelling bees.

\section{Negative Influence}

One need not teach very long at the

Alfred A. ARTH is at the University of Wyoming, Laramie; Lucille M. Freeman is at the University of Oklahoma, Ada; and Edward J. Lawton is at the College of Charleston, S.C. middle level to observe the degree to which such activities can negatively influence student attitudes toward school.

While middle level students are not usually sophisticated enough to challenge such teacher actions as an invasion of personal academic privacy, they do commonly decrease their degree of cooperation with the teacher. Students who are required to participate in a competitive activity for which they are ill-prepared, and which for them holds no possibility of success, may reasonably question whether the schooling process deserves their cooperation. Middle level students are very sensitive to the faimess of an activity.

The decision to compete is routinely made for students by a teacher who believes that competition per se is a positive experience. Deciding if students are to compete is one decision that educators need to examine carefully, par- 
ticularly in relation to middle level students.

Only after the following five concerns have been agreed on by the student and the teacher, should the transescent student enter into public competition.

l. Mastery. A degree of mastery sufficient to succeed is a prerequisite for meaningful competition. One must learn the concepts before one can call upon that knowledge in a competitive situation. This point is often overlooked by those planning competitive classroom activities.

Consider the middle level educator who elects to "motivate" students to learn a new concept through the use of a competitive board game. Those who rapidly gain or already understand the concept, and there will be a few, will be successful. Those who have not attained whatever minimal level of mastery is necessary are at a distinct disadvantage, and they know it. If no possibility exists for an individual to be successful in the competition, it cannot be a meaningful learning activity.

2. Competitive Skill. Some students may succeed in either the rote recall, awareness, convergent thinking, divergent thinking, or decision-making range of intellectual interaction. The intellectual area being challenged should be identified by the teacher. $\mathrm{He}$ or she could state to the class: "This 'game' will demand rote recall skills. Check your memories. Who is ready to compete?'”

Competition only in the area of rote recall allows only those students proficient in this area to be successful. Ideally, there should be competition offered to students in the areas of awareness, convergent thinking, divergent thinking, and decision making as well.

3. Entering Competition. The student must be willing to compete. Willingness to enter a competitive situation is often influenced by the student's degree of social acceptance or power. A high degree of social power may enable a student with limited ability to compete comfortably. At the same time, the student with a high degree of social power may feel pressure to perform in a predetermined manner. The student with a low degree of social power may be reluctant to compete, however, as may the student who is not particularly outgoing, or who doesn't like being the center of attention.

The manner in which teams are chosen may also cause an unwillingness to compete. Permitting team "leaders" to select team members leaves those chosen last in a difficult position; they may understandably resent a public demonstration that their peers did not want to choose them for a competitive team activity. Whether points are obtained through team consensus or through individual effort may also affect a student's willingness to compete.

In addition, willingness to compete may depend on whether winning will be achieved through chance, skill, strategy, or persistent effort. Transescent students tend to confuse chance with skill, or skill with strategy. Clarifying the type of ability necessary for successful competition is an important aspect of encouraging involvement. At the middle level, students need the teacher's assistance in clarifying which factors are important for which competitive situations.

It is not unusual to find that a successful student is very reluctant to com- 
pete, because failure is seen as such a negative event. A less successful student may see the competition as less important.

Students must understand what ability is required in order to make an accurate decision about whether or not to compete, and they need opportunities to try a variety of competitive situations. Given the opportunity to make the decision to compete on the basis of real factors, students will learn how to evaluate personal abilities and strengths as well as how to select attainable goals.

Students who are required to participate in a competitive activity for which they are illprepared, and which for them holds no possibility of success, may reasonably question whether the schooling process deserves their cooperation.

In addition, students need to understand failure and its relationship to successful people. Could the man who held the league strike-out record (Babe Ruth) be a success? Could a man who lost his freshman college presidential race (John F. Kennedy) be a success? These examples and the many others that can be found in the biographies of successful persons can help to convince a student that he or she can go on after a public failure.

Transescent students can benefit from the problem-solving discussion that follows unsuccessful competition. Questions such as "Why did you fail this particular encounter?"' must be pursued past "because."

4. The Time To Compete. The student must be taught when to compete and when to remain a spectator, and three types of competition should be available: competition with self, with others, and with authority.

Young children believe that chance or other people are the influential factors in their lives. Competition with self teaches the middle level student to examine the influence of outside forces on the outcome of an event.

Competition with self allows the transescent student to try to do things that may provide a higher degree of risk related to personal success than ever before. It should be noted that this is only an initial stage of self-testing and selfevaluation within the full gamut of the student's emerging social, emotional, physical, and intellectual abilities. Selfcompetition can encourage the student to try, free from teacher grading, a series of advanced problems or activities.

Allowing students to select questions from boxes which indicate their difficulty can provide the basis for selfchallenge. The teacher could ask rote recall questions on the "regular test" and then give bonus points for correct answers to any questions selected from the "Cause and Effect Box" or the "Comparison Box" or the "Supposition Box" or the "Complex Relationship Box."

"Brainteasers" are usually available only to those who finish first. This robs the slow but accurate thinker of a chance for self-competition. A willingness to experiment with the boundaries of personal abilities should be the only selec- 
tion criterion for controlled brainteaser activities.

Competition with others is the most common form of competitive classroom activity. A simple rule should govern this form of classroom activity: Only those who believe they can win should compete. The rest should enjoy the safety of a participant position. This position is made secure by the knowledge that the teacher will continue to ask for participants if they are ready for the activity, but will never force participation.

Competition with authority is caused by teachers gambling on semi-known events or sources from situations directly related to classroom activities. Examples would be giving extra credit for homework on evenings when the class median score is above a certain percent, or allowing students to rearrange their seating if there are more than 137 announcements by the principal's office in a one-week period.

Students must understand what ability is required in order to make an accurate decision about whether or not to compete, and they need opportunities to try a variety of competitive situations.

The gifted and the highly motivated often hesitate to guess. When the model student is willing to take a chance in certain situations where the loss is acceptable through competition with the class, the idea of approximation becomes a real choice.
Ratios of chance of success and the "longshot"' as a plausible option in some situations need to be discussed by the class. A review of the current luxuries and how many came about because of a "scientific guess" may serve as a reminder that life has a center core and an outer limit, both of which can cause beneficial by-products for mankind.

5. Winning. In addition to learning to assess and select various competitive situations and to understand failure, the early adolescent also needs assistance in learning to seek and accept success. The student must be able to accept the idea of being different due to superior intellect or skills.

Gifted students, whose abilities enable them to win often, may find winning a particularly uncomfortable experience because of the social cost that it may carry. They may find themselves in competitive situations in which the outcome is actually predetermined. They win because they are competing against students who just happen to be in the same classroom and who lack the skill or ability to compete on the same level. Middle level students are quick to recognize when they have been "set up" by the system. They also recognize a win in such a situation as an easy win at the expense of others. Neither the winners nor the losers are left with respect for the process when competition is forced among students of very unequal abilities.

\section{Conclusion}

Can various types of competition be introduced and reinforced in some way through the curriculum? Can teachers be prepared to work with transescents in a variety of experiences to help students 
select into competitive situations? Can these curriculum and instructional strategies aid teachers in knowing when and how to use competition as a motivational and instructional device? The answer to all three questions can be "yes."

Giffed students, whose abilities enable them to win offen, may find winning a particularly uncomfortable experience because of the social cost that it may carry.

The ambivalence of transescence is well-documented, but a summary may help put the competition issue and the school's response in perspective. This is a developmental stage at which low selfconcept and sensitivity to criticism leads to concern about the opinions of others, particularly peer opinion. Middle level students compare themselves, their abilities, and their accomplishments to the "ideal." The realization that the ideal is usually an unrealistic standard is a valuable discovery for the young adolescent. More accurate self-evaluation of ability and performance enables students to set challenging, but achievable, personal goals.

The young adolescent may be unaware of exactly which competencies he does possess and to what degree. The rapid increase in physical development and changing abilities to manipulate academic material may make the student either more or less able to compete with age-mates in areas he has come to feel comfortable in. The student who is functioning on a concrete level may find that some of his classmates are able to comprehend material in a different way than he does, making math competition difficult for the first time. The student who has previously competed successfully in physical education activities may find that his growth pattern now makes it difficult enough to participate, let alone compete. Changes in individual prowess require young adolescents to reevaluate their abilities.

Middle level students are also becoming interested, and often more effective, in assuming responsibility. This is also the time when youngsters need greater opportunity to make decisions. All of that translates into the following challenge: to establish programs and techniques which give students an opportunity to explore, to make decisions, and to take on responsibilities that will result in enough success to improve self-concept. Such a process could obviously motivate increasing student involvement in competitive activity, and a more positive student reaction to competitive activities designed by the teacher.

This provides sufficient reason for implementation of several programs. One example is the adviser-advisee or the walking advisement approach. These programs can result in a student's identification with an adult who can encourage exploration and decision making. This can be done through homebase activities and through existing programs in the school. The teacher can weigh the extent of challenge necessary in relation to the probable success factor. A more individualized guidance and support system can be devised by having the teacher share information 
with other teachers regarding student progress in attaining a more positive self-concept.

The same benefit can be realized as teachers work with students in exploratory activities, creative and practical arts, and intramural athletic programs. When possible, teachers should encourage student involvement, balance participation and success, emphasize strengths and interests, and make realistic suggestions about other activities that students might try.

Familiarity with the nature of the competitive process helps students to accurately evaluate the result of personal involvement.

By participating in a variety of activities, a student can make better judgments on what constitutes luck as opposed to skill, and whether a need exists for persistent effort and varying strategies.

Competition permeates most school environments. Students obtain either more or less of the teacher's attention. Grading practices commonly impose comparative grading. Participation in cocurricular activities may be dependent upon successful competition for grades within the classroom. There is competition for friends and competition among friendship groups.

Middle level students need to initially experience competition within the framework and safety of a small group. Shared effort, and shared success and failure are excellent precursors to individually experienced success and failure.

An examination of the requirements of competitive situations in relation to personal strengths and weaknesses assists students in judging when to compete. Awareness of the personal cost of both success and failure permits students to make an informed choice about involving themselves in competitive situations. Familiarity with the nature of the competitive process helps students to accurately evaluate the result of personal involvement.

Walking advisement programs, exploratory experiences, intramural activities, and involvement in a range of inclass competitions can support students as they learn the competitive process. The ability to compete can be viewed as a necessary auxiliary skill that deserves attention from curriculum planners.

Competition is a significant reality of life. There is benefit in controlled, effective introduction of this reality, and middle level teachers are the key.

\section{The Scope of Instruction}

"Instruction is limited to what the teacher does; education is measured by what the pupil is rendered competent to perform." 